\title{
An Assessment of Computational Fluid Dynamics and Semi-empirical approaches for Vertical Axis Wind Turbine Analysis
}

\author{
Elhadji Alpha Bah, Lakshmi N. Sankar, Jechiel I. Jagoda \\ School of Aerospace Engineering, Georgia Institute of Technology, Atlanta, GA 30332-0150, USA
}

\begin{abstract}
Vertical axis turbines have many attractive features and are well suited for extraction of wind and hydrokinetic energy. At low angular velocities, the rotor blades momentarily experience high angles of attack and move in and out of stall. This gives rise to unsteady aerodynamic loads that may cause vibration and structural fatigue. The high pressure drag and loss of lift during dynamic stall also leads to a lower efficiency compared to horizontal axis systems. In this work, a three-pronged approach with increasing complexity is used to understand and model this complex phenomenon, for a representative system. Empirical curve fits are first used to map the efficiency of the turbine as a function of tip speed ratio. An existing double multiple streamtube methodology (DMST) is next used, with a variety of empirical methods for modeling dynamic stall. Finally, computational fluid dynamics (CFD) results are presented and compared with test data and the DMST approach. It is concluded that DMST approaches are well suited for screening and designing vertical axis wind turbine configurations, followed by detailed modeling of the physical phenomena using well validated CFD tools.
\end{abstract}

Keywords-CFD; vertical axis wind turbines (VAWT); dynamic stall models

\section{INTRODUCTION}

Vertical axis wind turbines (VAWT) have a relatively simple, rugged construction compared to horizontal axis wind turbine systems (HAWT). They have the ability to operate and produce power independent of the wind direction, and avoid complex pitch control and RPM control found on horizontal-axis wind turbines. They are, however, strongly affected by dynamic stall, particularly when the tip speed is a small multiple of the wind speed. A significant part of the kinetic energy contained in the oncoming wind is lost in swirl and vortices. As a result, VAWTs have a lower power production and efficiency $(<$ $40 \%)$ compared to HAWTs ( $50 \%)$.

Efficient and reasonably accurate methods are needed for understanding and modelling this complex phenomenon, as an important first step towards designing next generation VAWT systems. In this work, we examine the ability of semi-analytical and empirical methods for modelling VAWT aerodynamics and power production. These methods are known to be well-suited

$$
C_{P}=C_{1}\left(\frac{C_{2}}{\lambda_{i n v}}-C_{3} \theta-C_{4} \vartheta^{C_{5}}-C_{6}\right) e^{-C_{7} \lambda i n v}+C_{0} \lambda_{i n v}
$$

Where $c_{i}[i=0,9]$ are empirical coefficients determined to best match the data from a given turbine model; and is the blade pitch. $\lambda_{\text {inv }}$ is given by for exploring a large design space and for selecting a small subset of configurations that merit further analysis and detailed design. We examine computational fluid dynamics as a necessary second step in understanding the underlying complex flow physics. The objective of this work is to describe and assess this three-pronged approach for modelling an existing vertical axis wind turbine system for which reliable field data is available.

\section{Description of the Available Test DatA}

This study makes extensive use of Open-Field experimental data collected by the Angstrom Lab Vertical axis group in Uppsalla University (SWE). A detailed description of their data set and related analytical studies may be found in the works of Osterberg (2010), Kjellin et al. (2011), Kjellin (2012), Deglaire et al., Erickson et al. (2011).

A $12 \mathrm{~kW}$ straight bladed VAWT has been chosen for detailed analysis. The balde is made of NACA 0021 sections. The chord is $25 \mathrm{~cm}$. The blade length is $5 \mathrm{~m}$. There are 3 blades. The blade radius is $3 \mathrm{~m}$. The hub height is $6 \mathrm{~m}$.

It should be noted that the blade chord tapers linearly over the last one meter of the blade span near both blade tips, with a tip chord of $15 \mathrm{~cm}$. Each of the blades is connected to the central hub by two struts that are attached to the blade near the spanwise locations where taper begins. This turbine is rated to generate $12 \mathrm{~kW}$ at 12 $\mathrm{m} / \mathrm{s}$ wind speed at $127 \mathrm{RPM}$.

\section{EMPIRICAL MODELS}

During the conceptual design space, the designer is often interested in knowing how the power coefficient $\mathrm{Cp}$ is influenced by the geometry and the operating conditions. In this section, the blade geometry is fixed, and we limit ourselves to modelling the variation of the power coefficient as a function of the tip speed ratio and the pitch of the blade. The empirical curve fit used here was originally proposed for horizontal axis turbine in Man et al. (1981) and reproduced in Heier (1996). This formulation was subsequently adapted to vertical axis turbines by Eid et al (2006) and Omijeh et al. (2013). 
Here is one-half the tip speed ratio $\mathrm{R} / \mathrm{V}_{\text {Wind }}$.

The empirical coefficients are determined using a nonlinear least square fitting. The available experimental data for the coefficient of power has considerable scatter for tip speed ratios above 3 . The present curve fit was therefore conducted using only the low tip speed ratio dat. The set of coefficients obtained are in Table 1. The correlation between the curve fit and test data is shown in Figure 1. Very reasonable agreement is obtained.

TABLE I. EMPIRICAL COEFFICIENTS

\begin{tabular}{|l|l|l|l|l|l|l|l|l|l|}
\hline $\mathrm{C}_{0}$ & $\mathrm{C}_{1}$ & $\mathrm{C}_{2}$ & $\mathrm{C}_{3}$ & $\mathrm{C}_{4}$ & $\mathrm{C}_{5}$ & $\mathrm{C}_{6}$ & $\mathrm{C}_{7}$ & $\mathrm{C}_{8}$ & $\mathrm{C}_{9}$ \\
\hline 0.0052 & 0.408 & 122.68 & 0.424 & 0.0226 & 1.026 & 18.025 & 11.893 & 0.126 & 0.064 \\
\hline
\end{tabular}

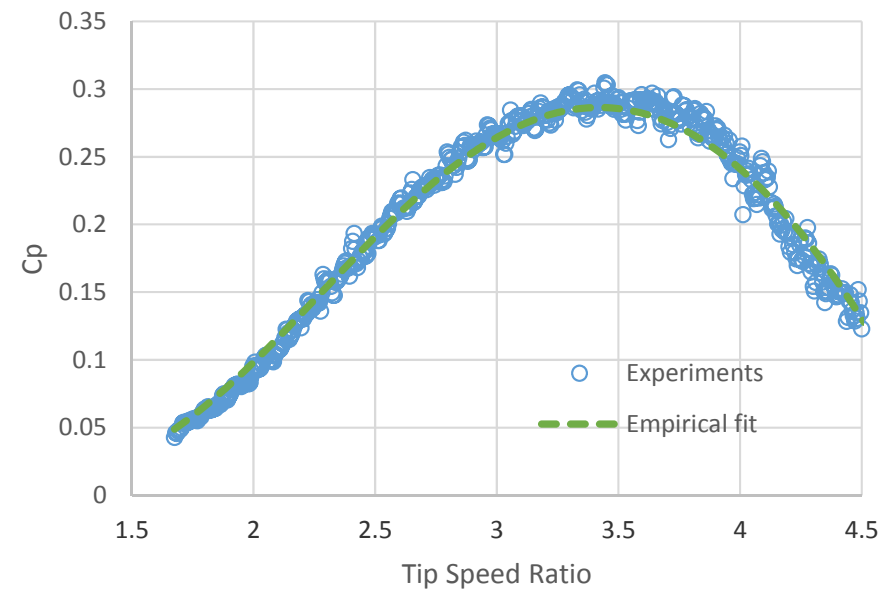

Figure 1. Empirical Curve Fit for the Variation of Power Coefficient for the Rotor Described in Table 1.

\section{Double Multiple Streamtube Model}

Empirical methods, such as the ones shown above, are limited to a few design parameters (radius and height of the VAWT, tip speed ratio, and blade pitch. These methods are not adequate for the second stage of analysis where the aerodynamic data associated with a family of airfoils must be used to screen optimum single and multielement airfoil shapes, specifically the variation of lift and drag coefficients with angle of attack. Blade element theory is well suited for this stage of the study, and may be efficiently implemented using Matlab of Fortran scripts, or even on a spreadsheet. In the present work, a double multiple streamtube model (DMST) developed by Paraschivoiu (1988, and 2002) is used.
In the present work, a number of previously dynamic stall models have been explored within the context of the DMST model, and the results are shown in Figure 2. The models described by Gormont (1973) and Berg (1983) considerably overpredict the performance at high tip speed ratios, while Masse (1981) under-predicts it. At this writing, effort is underway to better tune the coefficients in these model for improved and accuracy. For instance the Gormont's model does not contain a dynamic stall correction when the variation of the angle of attack $\mathrm{d} / . \mathrm{dt}$ is negative, whereas other models, e.g. the original Gormont model, do account for this. Other deviations between the predictions and the test data are attributable to the fact the turbine has a moderate solidity $(0.25)$ while the DMST generally gives best results for low to moderate solidity values. 


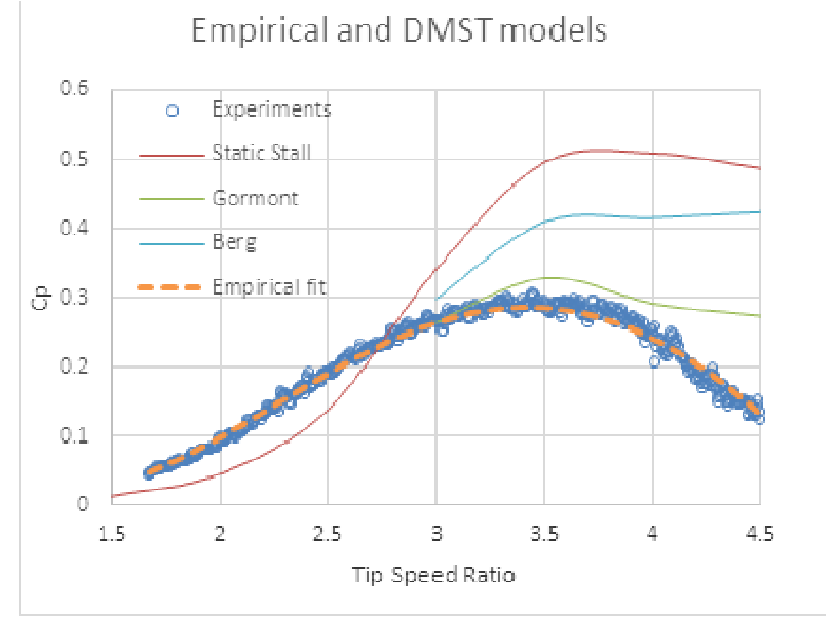

Figure 2. Effects of Dynamic Stall Models within the Double Multiple Stream Turbe Methodology on the Prediction of Power Coefficient

\section{COMPUtational Fluid Dynamics ANALyses}

We finally turn our attention to physics based models that have fewer empirical constants - only those that are needed to model the eddy viscosity. In this study, a twodimensional CFD study is conducted using the commercial CFD tool Fluent ${ }^{\circledR}$. The computational domain consists of two main sub-domains $=$ the rotor which is a sliding mesh and a stationary mesh. The center of rotation is placed at four rotor-diameter lengths downstream of the velocity inlet. The pressure outlet is placed eight diameters downstream of the center of the rotor. The sides are non-slip walls five diameters on both sides of the center line. The lateral (outer) boundaries are thus 5 rotor diameters away. The outer boundaries of the flow filed are considered far enough to have any effect on the rotor.
Because CFD studies are costly, it has not been possible to obtain power coefficients for the entire range of tip speed ratios of interest in practice. Rather, the variation of the blade torque coefficient as a function of azimuth is examined for a reference blade. The other two blades will have a similar variation, with a phase lag of 120 and 240 degrees, respectively.

The results are presented in Figure 3. The CFD simulations predict a higher torque coefficient over much of the azimuth. This deviation may be caused by a number of factors. First of all, this is a 2D simulation that is being compared to a full scale open-field data. The present 2D model does not take into account the blade taper near the tip or the tip losses. Our simulation also does not include the effect of the struts and the hub.

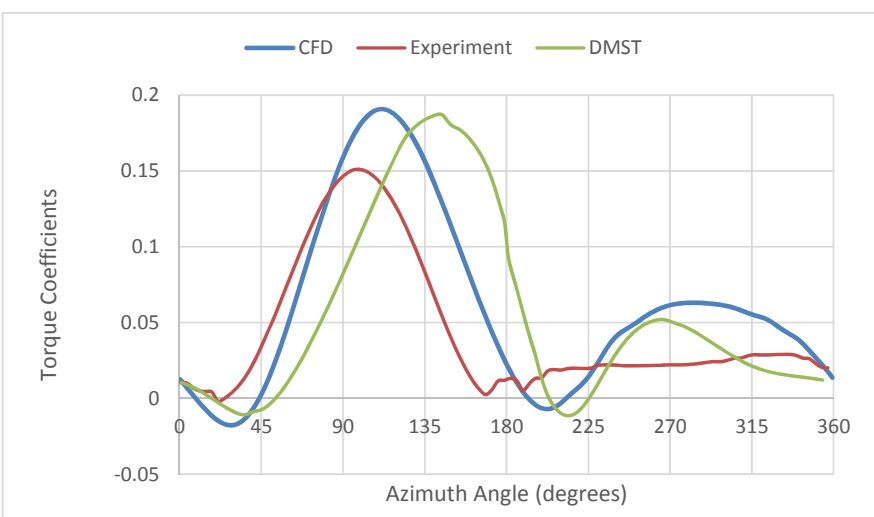

Figure 3. Variation of Torque Coefficient with Azimuth for a Reference Blade

The DMST model has behaves similar to the CFD analysis, but there is a significant phase lag between the test data and the DMST model, possibly indicating that stall is triggered at higher angles of attack in the empirical model. The post stall behaviour is acceptable, given the highly empirical nature of the dynamic stall model. 


\section{CONCLUSIONS}

In this work, a three-pronged approach with increasing complexity is used to understand and model this complex phenomenon, for a representative system. Empirical curve fits are first used to map the efficiency of the turbine as a function of tip speed ratio. An existing double multiple streamtube methodology (DMST) is next used, with a variety of empirical methods for modeling dynamic stall. Finally, computational fluid dynamics (CFD) results are presented and compared with test data and the DMST approach. It is concluded that DMST approaches are well suited for screening and designing vertical axis wind turbine configurations, followed by detailed modeling of the physical phenomena using well validated CFD tools.

\section{REFERENCES}

[1] Bah, E.A.A., Sankar, L., and Jagoda, J., (2013a) Investigations on the use of multi-element airfoils for improving vertical-axis wind turbine performance, "AIAA-2013-1109, 51st AIAA Aerospace Sciences Meeting and Exhibits", Jan. 7-10, 2013, Grapevine, TX.

[2] Bah, E.A.A., Sankar, L., and Jagoda, J., (2013b) Numerical Investigations on the use of multi-element airfoils for vertical axis wind turbine configurations, "Proceedings of the ASME 2013 Gas Turbine India Conference", Dec. 5-6, 2013, Bangalore, India.

[3] Berg D.E., (1983) An Improved Double-Multiple Streamtube Model for the Darrieus-Type Vertical Axis Wind Turbine, Sixth Biennial Wind Energy Conference and Workshop, pp. 231-233.

[4] Deglaire P., Eriksson S., Kjellin J., and Bernhoff H., Experimental results from a $12 \mathrm{~kW}$ vertical axis wind turbine with a direct driven
PM synchronous generator "EWEC 2007 - European Wind Energy Conference \& Exhibition”, Milan, Italy, May. 7-10, 2007.

[5] Eid A.M, Adel-Salam, M. and Abdel-Rahman, M., (2006), Vertical-axis wind turbine modelling and performance with axialflux permanent magnet synchronous generator for battery charging applications, 11th International Middle East Power Systems Conference.

[6] Erickson, D.W, Wallace, J.J., and Peraire, J., (2011) Performance Characterization of Cyclic Blade Pitch Variation on a Vertical Axis Wind Turbine, "49th AIAA Aerospace Sciences Meeting including the New Horizons Forum and Aerospace Exposition”, 4 - 7 January 2011, Orlando, Florida.

[7] Gormont R.E., (1973) An Analytical Model of Unsteady Aerodynamics and Radial Flow for Application to Helicopter Rotors, U.S. Army Air Mobility Research and Development Lab Technical Report 72-67.

[8] Heier, S., "Grid Integration of Wind Energy Conversion System", Wiley 1996

[9] Masse, B. (1981) Description de deux programmes d'ordinateur pour le calcul des performances et des charges aerodynamiques pour les eoliennes at axe vertical, IREQ-2379.

[10] Omijeh B.O., Nmom, C.S., and Nlewem E., (2013) Modeling of a Vertical Axis Wind Turbine with Permanent Magnet Synchronous Generator for Nigeria International "Journal of Engineering and Technology" Volume 3 No. 2, February 2013.

[11] Osterberg D., (2010), Multi-Body Unsteady Aerodynamics in 2D Applied to a Vertical-Axis Wind Turbine Using a Vortex Method, Thesis, Uppsala University.

[12] Paraschivoiu, I., (1988) Double-multiple streamtube model for studying vertical-axis wind turbines, Journal of Propulsion, Vol. 4, No. 4, 1988, pp. 370-377.

[13] Paraschivoiu, I., (2002) "Wind turbine design: with emphasis on Darrieus concept," Polytechnic International Press, 2002. 